\title{
Delivering a dignified death in a challenged national health system
}

Welcome to a New Year and a new look Clinical Medicine. As I write this in the first few days of 2018 the struggles of the NHS are writ large in the national media: the wrong flu vaccine, the battleground medicine being performed in corridors of overstretched hospitals, and deferred operations for anyone expecting routine surgery in January. So, as predicted, the NHS is under significant pressure. As general physicians we, alongside our emergency medicine colleagues, tend to bear the brunt of these periods of sustained demand, and, as eloquently expressed by many senior doctors on the national news over the last few days, patients appear to be sicker and frailer than ever before, meaning that many of our initiatives to keep people out of hospital are not as effective as had been hoped. A combination of these factors means that many more frail and elderly patients will be admitted to our acute medical wards and a not-insignificant proportion will die following admission. So against this backdrop, in addition to the usual CME, original research and educational offerings, and as a response to a challenge from the president of the RCP to highlight big issues across all our publications in our 500th year, I wanted to focus a spotlight on improving the quality of end-of-life care.

One of the greatest challenges as a clinician is how to facilitate a good death in a challenged healthcare system. I do not refer to the optimal management of the underlying pathology, but maintenance of care and compassion for those who do not need more acute medical input. The same quality of care is required to support and care for the patient, their family and indeed occasionally their wider network.

To that end, I have commissioned a series of articles across Clinical Medicine, Future Healthcare Journal and the RCP Commentary to explore the clinical, non-clinical and personal aspects of optimising death. This is a challenging subject encompassing moral and ethical, legal, ${ }^{1}$ religious, ${ }^{2}$ scientific medical $^{3}$ and managerial domains that spans primary, social and secondary care. ${ }^{4}$ I hope we achieve, in some small measure, a positive focus on this important aspect of our professional care. It is apt that this edition combines CME in acute medicine, a specific look at the strengths and limitations of the NEWS score in acute injury ${ }^{5}$ (which is particularly timely as the revised NEWS has just been released $)^{6}$ and a focus on many issues that affect the elderly. I hope this combination offers practical and helpful education and thought-provoking articles across the whole spectrum of care we deliver, both in the acute life-saving domain and at the end of life.

\section{References}

1 Wills C. Legal and practical issues at the end of life. Clin Med 2018:18:32-4.

2 Choudry M, Latif A, Warburton KG. An overview of the spiritual importances of end-of-life care among the five major faiths of the United Kingdom. Clin Med 2018;18:23-31.

3 Star A, Boland J. Updates in palliative care - recent advancements in the pharmacological management of symptoms. Clin Med 2018;18:11-6.

4 Millington-Sanders C. Passing the baton of trust: the Daffodil Standards. Clin Med 2018;18:9-10.

5 Faisal M, Scally A, Elgaali MA et al. The National Early Warning Score and its subcomponents recorded within $\pm 24 \mathrm{~h}$ of emergency medical admission are poor predictors of hospital-acquired acute kidney injury. Clin Med 2018;18:47-53.

6 Royal College of Physicians. National Early Warning Score (NEWS) 2: Standardising the assessment of acute-illness severity in the NHS updated report of a working party. RCP, 2017. Available online www. rcplondon.ac.uk/projects/outputs/national-early-warning-score-news-2 [Accessed 10 January 2018].

Wing Commander Ed Nicol Editor-in-chief

$\begin{array}{llll}\text { Members of the editorial board } & & & \\ \text { Wing Commander Edward Nicol } & \text { Prof Tahseen Chowdhury } & \text { Dr Alexandra Lake } & \text { Dr Mehool Patel } \\ \text { Editor-in-chief } & \text { Dr Nick Cork } & \text { Dr Tom Levett } & \text { Dr Gerrard Phillips } \\ \text { Cono Ariti } & \text { Dr Albert Edwards } & \text { Dr Nicola Lomax } & \text { Dr Roby Rakhit } \\ \text { Statistical editor } & \text { Dr Kate Evans } & \text { Prof Philip MacCarthy } & \text { Dr Jo Rimmer } \\ & \text { Dr Johanna Feary } & \text { Prof Yash Mahida } & \text { Prof Phil Smith } \\ \text { Dr Michael Almond } & \text { Dr Maggie Hammersley } & \text { Dr Chris Marguerie } & \text { Dr Angela Star } \\ \text { Mr Paul Belcher } & \text { Dr Dylan Harris } & \text { Dr Ravik Mascarenhas } & \text { Prof Cameron Swift } \\ \text { Prof Rodger Charlton } & \text { Prof Brian Hurwitz } & \text { Prof Martin McKee } & \text { Dr Rhys Thomas } \\ \text { Dr Tim Chevassut } & \text { Dr Nicola Jones } & \text { Dr Andrew Medford } & \text { Dr Duncan Wilson } \\ & \text { Dr Vikas Kapil } & \text { Dr Rahul Mukherjee } & \text { Dr Juliet Wright }\end{array}$

